\title{
Educação a serviço da alienação: projetos de lei que ameaçam a educação transformadora sonhada por Paulo Freire
}

Resumo Este artigo busca analisar os recentes projetos de lei criados para reprimir o pensamento crítico nas escolas brasileiras e submetê-las plenamente às exigências e aos pressupostos neoliberais. São variadas as maneiras de atacar a liberdade e a autonomia de educandos e educadores. Elas vão desde a abolição de disciplinas fundamentais para uma formação cidadã, como a Sociologia e a Filosofia, até a criminalização dos docentes de Humanas, passando pelo estabelecimento de uma educação produtivista, voltada apenas para notas. Todas estas medidas instituem oficialmente a opção por aquilo que Paulo Freire, o maior educador brasileiro, tanto criticou: uma educação alienante a serviço do grande capital.

PalaVRas-chaVE: Paulo Freire; Educação; Neoliberalismo. 


\title{
Education at the service of alienation: bills that threaten Paulo Freire's dream of transformative education
}

\begin{abstract}
This paper seeks to analyse recent bills which were drafted with a view to repressing critical thinking in Brazilian schools, thus forcing these schools to fully abide to neoliberal premises and demands. There are different ways in which the liberty and autonomy of pupils and educators alike can be put in risk. These range from the abolishment of subjects which are essential for shaping citizens, such as Sociology and Philosophy, to the criminalisation of Humanities teachers, including the fomentation of a more productivist approach to education whereby only grades matter. These different measures officially introduce an option for something which was greatly condemned by Paulo Freire, Brazil's greatest educator: an alienating education at the exclusive service of big business.
\end{abstract}

KEYWORDS: Paulo Freire; Education; Neoliberalism.

O projeto de lei número 6.114-A de 2009, (originado do PLS 403 de 2007, de autoria do senador Wilson Matos, do PSDB do Paraná), defende a criação de uma prova para avaliar os professores e professoras atuantes na Educação Básica em todo Brasil, tanto na rede privada quanto na pública. Ele institui assim o Exame Nacional de Avaliação do Magistério da Educação Básica (ENAMEB), mas não apresenta a finalidade de tal avaliação; sem prever nenhuma medida para melhorar o rendimento destes(as) profissionais, explicar os critérios avaliativos ou descrever o método de avaliação. Esta iniciativa parece ser fruto da falta do prestígio e da desconfiança com que são vistos os(as) profissionais da área, em meio à sociedade brasileira atual.

Ao projeto de lei 6.114-A/2009 foi apensado o projeto de lei 1.088/2007, de autoria do deputado Gastão Vieira, do PROS do Maranhão. Se o 6.114-A/2009 estabelece que a avaliação dos profissionais da Educação poderá ser utilizada para sua progressão na carreira, o 1.088/2007, se aprovado, criaria uma avaliação credenciadora, semelhante à prova da $\mathrm{OAB}$, que seria pré-requisito "para o exercício do magistério na educação básica”. Ele estipula que este exame seja realizado anualmente ou com uma frequência ainda maior; enquanto o projeto de 2009 traz avaliações quinquenais. O PL 1.088/2007 também utilizaria essa avaliação para a progressão na carreira e justifica a medida fazendo referência a uma pretensa "tendência observada no cenário internacional", sem esclarecer em quais países nota-se essa tendência e quais as semelhanças entre eles e o Brasil, no que tange à Educação.

Uma vez que o que ocorre em outros países foi usado para justificar tal medida, é interessante relatar ao menos um caso que demonstre que esta "ânsia avaliativa" está longe de ser consensual no referido "cenário internacional". Ao contrário, em matéria de 18 de dezembro de 2013, oito anos após a apresentação do projeto 1.088, portanto, o mais prestigiado jornal português - o Público - trouxe a seguinte matéria: "PROVA DE AVALIAÇÃO DE PROFESSORES É CASO RARO NA EUROPA: 
$\mathrm{Na}$ Europa, entre os modelos de recrutamento de docentes predominam aqueles em que são as escolas, em conjunto com as autoridades locais, que contratam diretamente, em vez de um concurso nacional" ${ }^{1}$. Bem, nem é preciso citar mais outro trecho. O título e o subtítulo da matéria já são claros o suficiente. Há, sim, países em que estas avaliações são aplicadas, mas são a minoria na Europa, e estão muito distantes de poderem ter suas realidades comparadas à brasileira. No caso específico de Portugal, após intenso debate em torno da questão, o país acabou por cancelar essa avaliação docente, dois anos após criá-la. Venceu a ideia de que a profissão docente é rica e complexa demais para ser avaliada apenas por uma simples prova.

Além disso, educadores e especialistas portugueses afirmaram que a avaliação demonstra uma contradição interna do próprio Estado. A contradição está no fato de que os professores ou candidatos à carreira docente foram formados por instituições de ensino superior pertencentes ao Estado ou por ele reconhecidas e credenciadas. Assim, a avaliação coloca em dúvida a qualidade do próprio serviço oferecido por esta instituição ou por ela fiscalizado, demonstrando que ela desconfia de sua própria capacidade de fazê-lo. $\mathrm{O}$ índice de aprovação dos professores portugueses foi de $86 \% \mathrm{em}$ $2014^{2}$. Muito alto, sem dúvida. Ainda assim, foi grande a resistência da classe docente diante desta avaliação, tida como reducionista e incapaz de avaliar sua profissão.

Com o exemplo português e sua contextualização dentro da Europa, pretendeu-se questionar a justificativa apresentada pelo deputado do PROS para a criação da prova credenciadora. Cabe lembrar, porém, que não se pode utilizar exemplos estrangeiros de modo irrestrito, sem realizar um questionamento acerca das semelhanças e diferenças entre a realidade local e a de outros países. Aliás, foi isso que o deputado Gastão Vieira fez, em sua justificativa. Aqui, pretendeu-se apenas demonstrar que sua afirmação a respeito da "tendência observada no cenário internacional" é falaciosa; assim o argumento pode ser facilmente vencido, com as próprias armas que escolheu para si.

É preciso entender a qual lógica serviria esta prova no Brasil, tendo em mente que ela pode acabar por cumprir outra função, em um contexto distinto. O que se percebe é que, neste país, ela insere-se no eixo das políticas neoliberais com relação à Educação, que pensam a escola como uma empresa e buscam, acima de tudo, produtividade, já que não podem almejar sempre o lucro direto (não no caso da rede pública); ao menos, enquanto não alcançarem seu fim último, que, para alguns, seria a privatização cada vez maior da rede de ensino (EDUCAÇÃO E SOCIEDADE, 2016).

Avaliar, para a ótica neoliberal, é classificar e produzir um número que possa ser comparado com outros, definindo quem deve ser premiado e quem deve ser punido. Trata-se da lógica do mercado a adentrar os portões da escola com cada vez mais força. A este respeito, afirma Gentili:

"É o mercado de trabalho que emite os sinais que permitem orientar as decisões em matéria de política educacional. É a avaliação das instituições escolares e o estabelecimento de rigorosos critérios de qualidade o que permite dinamizar o sistema através de uma lógica de prêmios e castigos que estimulam a produtividade e a eficiência" (GENTILI, 1996, p.7). 
O que se deseja é transformar o intangível em algo mensurável; as complexas realidades humanas em meros gráficos e tabelas. Trata-se, por fim, de dizer aos professores que eles devem adaptar-se ao que o mercado espera deles; devem agir em conformidade com que lhes é imposto. Trata-se de uma vitória do capital sobre o saber e sobre as relações humanas; de uma humilhação daqueles que fogem à esta lógica e trabalham à margem da produção de mercadorias. Mesmo diante da intensa mercantilização do ensino e do saber, ainda há discípulos de Paulo Freire a lutar por uma educação humana e crítica. O mercado deseja expulsá-los de vez da escola e capturar esta instituição completamente para si, fazendo valer o paradigma repressivo e alienante da "educação bancária" (FREIRE, 2011c).

Vale a pena retomar este conceito de Freire, ainda que bem conhecido e difundido. Paulo Freire entende por "educação bancária" aquela em que o(a) professor(a) só "depositaria" informações sobre seus alunos e alunas, sem ajudá-los a operacionalizar esses dados e a usar deles para modificar a realidade em que vivem. Assim, semelhante a um cliente que dirige-se a um banco para ali depositar seu dinheiro, a informação é apenas entregue ao corpo discente, que deve memorizá-la, retendo-a consigo, mas sem constituir-se em senhor deste conhecimento. Bem como a instituição bancária deve apenas guardar o dinheiro dos clientes, sem dele se apossar. Assim, a informação trabalhada em sala de aula não chegaria nunca a constituir um conhecimento operacional, capaz de ser útil para entender o mundo e transformá-lo. Deste modo, a educação escolar cumpriria mais uma função alienante que libertadora; serviria aos interesses das classes dominantes e afastando as classes dominadas de uma relação com o saber que lhes permitisse conquistar direitos e poder.

Para Paulo Freire, "ensinar não é transferir conhecimento" (2011a); muito mais que isso, ensinar é criar uma intensa relação humana de trocas entre docentes e discentes, visando sempre a promover uma sociedade mais justa e igualitária, bem como indivíduos mais autônomos, maduros e felizes. A atividade docente deve promover um "empoderamento" dos alunos, de modo a permitir-lhes transformar sua própria realidade. Isso só é possível a partir de um educação transformadora, que permita o desenvolvimento da criticidade e a análise histórica das relações humanas. Assim, a função do educador está mais próxima do livre debate de ideias do que da transmissão de um saber pronto e acabado, assumido pela Pedagogia Tradicional como um conhecimento de valor intrínseco e incontestável. Essa Pedagogia Tradicional, tão criticada por Freire, produz a "educação bancária"; na qual os docentes detêm um enorme poder e aos alunos só cabe ouvir e tudo aceitar, sem jamais contestar.

A educação só é verdadeiramente transformadora quando o corpo discente não é incumbido de exercer um papel apenas passivo, de objeto a ser moldado sem oferecer qualquer resistência. Cabe aos alunos assumir o papel de construtores de seu próprio conhecimento, auxiliados neste processo pelo educador. São eles não meros espectadores de um espetáculo tradicional ou receptores de algo que já está pronto, mas constituem o próprio eixo central de toda relação educativa verdadeiramente libertadora. Assim, seu protagonismo deve ser resgatado e segundo Paulo Freire (2011b; 2011c), os mais céticos muito provavelmente se surpreenderão ao perceberem do que são capazes os mais incultos e despreparados educandos quando apresentados a um 
modelo educativo que os trata como sujeitos e não como meros objetos. Freire (2011b; 2011c) apresenta inúmeros relatos de suas práticas e afirma que as classes baixas geralmente mostram-se sedentas de educação e saber, mas não daquela "educação bancária”, padronizada, massificadora e alienante. O que elas almejam é uma educação que lhes permita compreender de fato o mundo em que vivem e expressar os anseios e desejos que alimentam. Para que tudo isso ocorra, entretanto, as pessoas não devem ser tratadas como meros "depósitos de informação". Paulo Freire (2011a) critica este modelo que exige do aluno apenas o desenvolvimento de uma absurda capacidade de memorização, ao invés de sua capacidade pensante.

Infelizmente, no entanto, a "educação bancária" continua a ser muito forte no Brasil. Ela atende aos interesses dos poderosos, que desejam tratar a prática escolar como mera mercadoria e impedir que as classes baixas desenvolvam o senso crítico e a prática cidadã de luta por um país mais justo. O próprio vestibular realiza uma importante função de dominação, uma vez que leva os alunos a competirem entre si por um número ínfimo de vagas nas universidades públicas. Assim, institui-se a antiga estratégia de "dividir para dominar", gerando a luta entre aqueles que são vítimas da mesma situação de injustiça. Basta analisar sumariamente o perfil dos ingressantes nas elitizadas universidades públicas brasileiras para perceber que o vestibular funciona não tanto para avaliar conhecimento e, sim, para medir riqueza. Ele não cumpre tanto a função de separar os inteligentes e cultos dos demais quanto a de separar os ricos dos pobres. Isso porque seu método avaliativo permite o sucesso apenas dos que foram condicionados para sobressaírem em relação aos demais no uso de suas capacidades mnemônicas e na atenção diante "armadilhas" e "subterfúgios": as chamadas "pegadinhas". Ora, este condicionamento não é realizado pelas escolas públicas, onde estuda a imensa maioria dos alunos e alunas das classes baixas. Pelo contrário, são as escolas particulares e os cursinhos que realizam essa preparação.

Nestas escolas e cursinhos, o saber e a consciência crítica ficam de lado; diante do imenso volume de informações que deve ser guardado, pouco importa analisá-los criticamente, demonstrar criatividade ou habilidades sociais. $\mathrm{O}$ que vale apenas é o desempenho numa avaliação que determinará o futuro deste aluno. Diante de algo tão absurdo e surreal (se bem que "naturalizado" por uma sociedade que não questiona suas estruturas de dominação), é comum que os alunos sofram cada vez mais cedo com crises de ansiedade e fadiga e desenvolvam inúmeros problemas psíquicos. Isso só agrada às escolas particulares e cursinhos, que lucram com este medo e esta sociedade desajustada. Quanto mais terrível, injusta e arbitrária for esta seleção (o vestibular), maior o lucro daqueles que oferecem promessas de sucesso.

Assim, os cursinhos pré-vestibulares e as escolas voltadas para estas provas, constituem já bastiões da educação tratada como mercadoria. Pouco importa aí a formação humana ou cidadã. Este modelo cria autômatos prontos a servirem às ordens superiores e aos objetivos consagrados pela sociedade capitalista, sem jamais questionar. O que impede a formação de pessoas criativas e críticas (FREIRE, 2011a). Ao contrário, vê-se muitas vezes a formação de ambientes extremamente conservadores, egocêntricos, alienados, hierarquizados e sádicos, nestes locais. Sobretudo, nos cursinhos. Não é à toa que são comuns tantos trotes violentos e verdadeiramente crimino- 
sos em nosso país. Falta que as investigações hoje timidamente realizadas acerca destas práticas sejam direcionadas também para estes cursinhos, que lucram ao ritualizar o acesso à universidade como algo árduo, mas recompensador; estimulando um clima hostil de cobrança e violência moral e psíquica em meio aos estudantes, que desemboca na catarse insana e doentia do crime disfarçado de brincadeira: o trote.

Nestes locais, impera a lógica do mercado, mas as escolas públicas, ainda muito distantes deste foco desmesurado no vestibular, resistem ainda aos ditames da mercadoria. Isso não significa, evidentemente, que elas sejam paraísos; oásis em meio ao deserto. São, entretanto, locais em que a ideia de "produtividade" nem sempre se destaca como eixo norteador de tudo que se faz ou se vivencia. A criação das avaliações externas para os alunos e agora para os professores vem transformar esta situação e inserir de vez também a escola pública no culto a essa máxima capitalista.

Num país em que a Educação historicamente constituiu-se num privilégio das elites durante séculos, sua popularização ainda hoje assusta os membros conservadores das classes altas, que tentam insistentemente controlá-la e torná-la "inofensiva". O estabelecimento desta avaliação para credenciamento profissional é um destes passos, bem como os diversos projetos que tentam calar o pensamento crítico construído no interior das escolas; seja retirando as disciplinas Sociologia e Filosofia da grade obrigatória do Ensino Médio (projeto de lei no 6.003/2013 do deputado Izalci Lucas Ferreira, do PSDB do Distrito Federal); seja tentando intimidar e criminalizar os professores de Humanidades com o infame projeto do deputado Rogério Marinho, do PSDB do Rio Grande do Norte (projeto de lei 1.411/2015), que prevê inclusive detenção de três meses a um ano para os educadores que praticarem o que ele chama de "assédio ideológico". Apresentar uma visão de mundo alternativa será institucionalmente crime, se aprovado esse projeto. Assim, como na época da Ditadura Civil-Militar (1964-1985), no auge da terrível Inquisição Espanhola, ou na Alemanha Nazista.

Isso tudo vem ao encontro do famigerado "Programa Escola Sem Partido", institucionalmente fundado no PL 867/2015, do mesmo deputado Izalci (PSDBDF), e no PLS 193/2016, do senador Magno Malta (PR-ES). Este programa almeja simplesmente proibir a discussão de visões críticas ao status quo nas escolas brasileiras. Ou seja, qualquer afirmação que destoe da ideologia dominante, será reprimida. Disciplinas como História, Sociologia ou Filosofia, portanto, devem ser excluídas ou deturpadas, "domesticadas", para que não mais sejam capazes de formar pensamento crítico. Algo temido pela elite representada por estes congressistas.

O objetivo deles é claramente imprimir um caráter meramente produtivista e neoliberal em nossas escolas, expulsando toda e qualquer preocupação com a formação humana e cidadã dos educandos. É uma tentativa de fortalecer a "educação bancária”, alienada e alienante, tão combatida por Paulo Freire (2011c). A escola almejada por eles é aquela capaz de formar crianças e adolescentes acostumados a decorar conceitos e fórmulas, mas estupidificados demais para pensar sobre sua realidade. Deseja-se, no limite, realizar em nossas escolas o mesmo que o governo japonês está tentando implantar em suas universidades: o fim das disciplinas e cursos da área de Ciências Sociais; tais como Sociologia, Antropologia e Ciência Política. Tentativa que tem encontrado resistência de significativa parte da classe acadêmica deste país ${ }^{3}$. 
A partir da medida neoliberal de premiação por resultados em provas já se conseguiu reforçar em nossas escolas os paradigmas da "educação bancária", fortemente enraizados nessas instituições; fortalecendo assim a Pedagogia Tradicional e sua suposta meritocracia, cabalmente vista como mentirosa desde 1964. É deste ano um livro de Bourdieu e Passeron que analisa como essa pretensa meritocracia nada mais é que um mecanismo de legitimação da desigualdade de classe presente na sociedade capitalista. Onze anos após este estudo, Foucault, em seu livro Vigiar e Punir, analisou o aspecto disciplinar da instituição escolar, mostrando que ela tem como paradigma a prisão e como este modelo contribui para o fortalecimento e a legitimação da dominação de classe. Assim, a escola tradicional - longe da escola democrática e cidadã que Paulo Freire buscou construir e que tem o amparo legal da LDB e da Constituição, no Brasil - é fonte de dominação e é esta a escola que desejam os legisladores dos projetos supramencionados.

O estabelecimento de um bônus na verba destinada às escolas públicas, cujos alunos que conseguirem melhores notas nas avaliações externas (como a Prova Brasil, o SARESP, ou a Provinha Brasil) é um fator de deslegitimação do trabalho docente - que vai muito além do que pode ser medido por uma simples avaliação escrita - e de descaracterização da relação entre o corpo discente e o conhecimento. Introduzir uma avaliação externa também para os docentes constitui o alcance do grau máximo de alienação no que tange à vida escolar (LOUZADA; MARQUES, 2015). Afinal, é pautar os educadores por uma lógica produtivista e mnemônica, quase que escolástica, e assim prepará-los para fazer o mesmo com seus alunos e alunas. Trata-se, portanto, do enaltecimento da prova escrita como instrumento perfeito de avaliação da inteligência; ou seja, trata-se da negação completa da obra de Piaget, que começou seus estudos sobre o aprendizado humano aplicando testes de QI, quando era ainda um mero assistente de Théodore Simon, mas logo se rebelou contra este procedimento, por achá-lo reducionista e falho diante da complexidade da mente humana (GARDNER, 2003).

Há que se recordar que não apenas o QI, mas toda avaliação, como toda e qualquer criação humana, é falha. Quem já lecionou, provavelmente percebeu o quanto é difícil saber o que os alunos têm apreendido de suas aulas e como é árdua a tarefa de fazer uma boa prova: equilibrada na distribuição dos conteúdos, desafiadora sem ser injusta, clara nos enunciados sem ser fácil demais, etc. Premiar as escolas que conseguem melhor desempenho é assumir a lógica repressora desmantelada pela análise de Foucault (2015) e fingir esquecer todas estas óbvias limitações de todo e qualquer instrumento avaliativo. Isto sem falar na crítica que se pode fazer ao critério de distribuição das verbas: ainda que as avaliações fossem perfeitas, não deveria ser destinada mais verba justamente para as escolas que têm ido mal e que por isso precisariam de mais recursos que as outras? A lógica é atender com qualidade a todos ou gerar uma competição por migalhas entre os membros da cotidianamente humilhada e mal paga classe docente? Trata-se do antigo estratagema de dividir para dominar ou da formação de cidadãos em igualdade de oportunidades? Almeja-se a correção das desigualdades ou a acentuação das mesmas? Estas são questões que não podem deixar de ser colocadas. Sandra Sousa é categórica quanto a essa medida neoliberal: 
A questão central nesta proposta não é buscar subsídios para intervenções mais precisas e consistentes do poder público, mas sim instalar mecanismos que estimulem a competição entre as escolas, responsabilizando-as, em última instância, pelo sucesso ou fracasso escolar. (SOUSA, 2001, p. 88).

O ENEM já há alguns anos divulga o ranking das escolas cujos alunos tiveram melhor desempenho nesta avaliação. Assim que surgiu, o ENEM representava uma quebra de paradigma com relação às provas dos mais concorridos vestibulares do país, oferecendo um exame que não se pautava tanto na capacidade de memorização de fórmulas e conceitos distantes do cotidiano da maioria das pessoas, mas na realização de operações mentais de diversas naturezas e na análise crítica da realidade social. Com o tempo, no entanto, o perfil da prova foi sendo alterado e hoje é predominantemente mnemônica e escolástica, como são os grandes vestibulares do país. Assim, o caráter classista desta avaliação foi sendo reforçado pouco a pouco, para confirmar e legitimar a dominação de classe, como as outras provas fazem. Não é por acaso que as prestigiadas universidades públicas estão repletas de membros das classes altas.

Em 2014, no entanto, o ENEM passou a divulgar não apenas o ranking das melhores escolas em sua avaliação, bem como ligou o desempenho à classe social do estudante. O que se percebeu foi uma comprovação evidente da tese de Bourdieu e Passeron (1964): o que determina o desempenho do aluno nesta prova, como em qualquer outra pautada nos mesmos paradigmas, é antes de tudo a classe social. Assim, a ideia de que a escola pública é ruim e a particular é melhor não passa de uma falácia e de uma arma ideológica nas mãos da burguesia, em meio à luta de classes. Afinal, se as escolas particulares costumam ir melhor não é porque são instituições mais qualificadas, mas simplesmente porque são frequentadas por uma parcela maior de alunos das classes mais abastadas. Quando se compara os alunos das escolas particulares e públicas no que se refere ao seu desempenho no ENEM, apenas 5\% (cinco por cento) dos alunos de escola particular conseguem ir melhor que a média de desempenho dos membros da mesma classe social que estão a estudar na rede pública. Ou seja, dentro de uma mesma classe social, não importa se o aluno provém de escola pública ou particular, pois em 95\% (noventa e cinco por cento) dos casos o desempenho é igual entre os alunos das duas redes de ensino; quando o rendimento do estudante de escola pública não se mostra superior ${ }^{4}$.

Não vale a pena adentrar aqui na discussão sobre quais fatores levam a esta considerável influência da dimensão de classe no desempenho estudantil, pois isso já foi largamente analisado por diversos autores, após o clássico estudo francês de 1964, já referido (BOURDIEU \& PASSERON, 1964). Cabe aqui ressaltar, entretanto, como esta lógica, apesar de todo o discurso a respeito da educação cidadã e democratizante, ainda está presente na organização estrutural de nossa Educação. Apesar da LDB e da Constituição defenderem paradigmas contrários a estes e prometerem o rompimento com a "educação bancária", ela mostra-se mais presente que nunca e continua a cumprir seu papel de legitimação da dominação burguesa; de superestrutura dentro do desumano sistema capitalista (MARX, 2007). 
Se uma prova para credenciamento de advogados é benéfica ou não, tratase de um assunto que não se discutirá aqui. Por não ser este o foco do artigo. Faz-se necessário ressaltar, porém, o caráter limitador e reducionista de uma avaliação meramente escrita para julgar uma prática tão complexa. A própria área jurídica implicitamente o reconhece, ao manter a prova oral como uma das fases necessárias para o ingresso na carreira da magistratura, por exemplo. No que se refere à Educação, devese ressaltar que o ofício docente pressupõe um desempenho prático, uma inteligência emocional e uma consciência cidadã que muito dificilmente podem ser auferidas por uma mera avaliação escrita. Avaliar um docente por seus conhecimentos técnicos (de Português, Matemática, Inglês, etc.) ou mesmo por aquilo que ele aprendeu sobre a Teoria Pedagógica e a Didática está longe de garantir que ele vá se sair bem enquanto profissional. Pode-se até comparar esta avaliação com uma que pretendesse avaliar um músico ou um dançarino apenas em função de uma prova escrita, sem permitir-lhes apresentar sua arte.

Ser professor é muito mais que saber os conteúdos ou mesmo ter formação pedagógica, pois pressupõe uma relação humana com os educandos, um compromisso para com o futuro, um diálogo cidadão com as famílias e toda a sociedade e, no Brasil, uma capacidade de resignação digna de um mártir ou a esperança cega de um louco (FREIRE, 2011a). Não há prova escrita que possa avaliar isso. Propor uma avaliação assim é desmerecer a profissão e não reconhecer suas especificidades. Aliás, não é de hoje que comumente ouvimos críticas a docentes que parecem saber o conteúdo técnico sobre o qual estão lecionando, mas que não possuem uma estratégia didática eficiente, de modo que os alunos pouco conseguem aprender. Esta crítica é constante no que se refere aos profissionais do Ensino Superior. A adoção desta prova credenciadora para os novos professores tende a aumentar ainda mais este mal, aumentando a parcela de profissionais do Ensino Básico que não se mostram capacitados para realizar a função docente. Capacitação, aliás, que não virá de mais teorias e mais provas, mas de um estágio supervisionado efetivamente proveitoso - o que demanda uma forte fiscalização, para que ele não seja burlado; como muitas vezes é - e de uma graduação que seja mais dinâmica e realista. Bem como, e este é o fator principal, uma grande valorização do profissional docente. Aliás, é o que recomendou a UNESCO ao nosso país, no estudo por ela realizado, em 2009.

Pavlov (1927) mostrou ser possível condicionar cães a aprenderem um símbolo. Estes animais salivavam quando ouviam uma sineta que o pesquisador sempre tocava ao alimentá-los. Em função do bônus, faz-se algo semelhante em nossas escolas. A preocupação já não é que o aluno aprenda - e muito menos formar um cidadão crítico, autônomo e feliz - mas que consiga ir bem nas avaliações externas, que garantem mais dinheiro para a escola. Semelhante aos cursinhos pré-vestibulares, verdadeiras fábricas de alienação massiva travestida de conhecimento, nossas escolas têm capacitado crianças e adolescentes a acertar as questões das provas, ainda que não façam ideia do que estão colocando no papel (LOUZADA; MARQUES, 2015). É como o analfabeto que sabe copiar algo da lousa ou de um livro, mas não sabe ler o que escreveu.

Esta lógica de sobrevalorização das provas e avaliações não foi criada pelas avaliações externas e pelo bônus, mas é profundamente reforçada por eles. $\mathrm{O}$ ato de 
treinar alguém para uma prova, sem se importar com mais nada, é extremamente alienante e infelizmente tem ocorrido desde a infância - e cada vez mais cedo. Mesmo no Ensino Infantil, docentes relatam que algumas crianças pedem-lhes para serem avaliadas por meio de provas, na ansiedade de sentirem-se preparadas para aquilo que já sabem ser a essência do "ensino" que lhes será ministrado no futuro. A sabedoria infantil já percebeu muito bem que a prova é a essência da escola tal como está instituída no Brasil. A prova e não o conhecimento! Nossas escolas, infelizmente, poucas vezes têm a oportunidade de (re)descobrir o poder transformador que o conhecimento tem e o quão cativante ele pode ser. Raros são os que nela são cativados a ponto de desejarem dedicar toda uma vida em prol da busca pelo saber. A maioria vê a escola como um desgosto e uma prisão - Foucault (2015) estava certo - e raríssimas vezes pegarão num livro, depois de libertos "das garras opressoras do monstro escolar".

Não é mero fruto do acaso o cenário de violência contra os docentes que nossas escolas apresentam. Ainda que a maioria dos estudantes brasileiros do Ensino Básico desconheça os relatos sobre os experimentos de Pavlov (1927), são como estes cães condicionados que as crianças e adolescentes deste sistema escolar altamente repressor, desigual e alienante se sentem. Daí a revolta e a violência. As escolas brasileiras sempre foram violentas, seguindo o modelo daquelas do velho continente europeu (FOUCAULT, 2015). Ao contrário do discurso conservador ainda hoje presente em parte da sociedade brasileira, os jovens do passado não obedeciam aos professores e professoras por respeito, mas por medo. Se o respeito tivesse reinado nesta época, não teria sido necessária a palmatória, a vara de marmelo e outros castigos físicos e morais. Hoje, na ausência deste instrumentos de violência física, subsiste a violência moral e psíquica contra os alunos, mas a violência também acontece em outro sentido: os docentes são muitas vezes vítimas de agressões físicas, psíquicas e morais. Com efeito, uma pesquisa realizada pela OCDE em 34 países apontou o Brasil como o país em que os professores mais sofrem com a violência dentro das escolas 5 . Além disso, um psiquiatra que trata de professores da rede pública de São Paulo há 25 anos afirmou à $\mathrm{BBC}$ que os professores reclamam mais da violência que sofrem nas escolas que dos baixos salários ${ }^{6}$. Não é difícil encontrar matérias de jornal sobre atos de violência por parte de alunos e famílias contra os professores. Quase semanalmente algum fato novo é noticiado. Isso sem mencionar as ofensas, injúrias, humilhações, chacotas e outras agressões morais que nunca são noticiadas, mas acontecem diariamente nas escolas brasileiras.

Não era apenas o medo do castigo físico que fazia com que os alunos aceitassem suportar o duro fardo da educação mnemônica, alienante e repressora. Havia por parte das famílias forte cobrança para que o desempenho escolar fosse satisfatório. Cobrança presente em todas as classes sociais e por um motivo muito simples: para todas elas, a escola representava a possibilidade de ascensão social e de garantia de uma vida melhor. Assim, ela representava um duro sacrifício; recompensado num futuro não muito distante (BOURDIEU, 2009). Há muito tempo, entretanto, não apenas no Brasil, a escola deixou de significar também para as classes baixas a possibilidade de ascender socialmente. Assim, seu peso tornou-se sem sentido; uma repressão gratuita. Por que então suportá-lo de bom grado? Muitos, de fato, rebelam-se e as escolas tornaram-se locais de duros embates entre docentes e alunos. A raiva e o rancor, antes laten- 
tes e recalcados, agora são expostos e chegam mesmo às vias de fato. Os cães de Pavlov (1927) ao menos eram recompensados. Nossos alunos são tratados como tais animais, mediante uma educação que não os quer pensando, mas apenas condicionados a responder corretamente a uma questão previamente conhecida e repetida à exaustão.

Seria um erro culpar os alunos ou suas famílias por este estado de coisas. Eles são as principais vítimas. Sua revolta é legítima, embora a violência jamais o seja. Trata-se de uma maneira errada de exprimir uma justa revolta. O que esperar, porém, de quem sempre foi tratado com violência, senão mais violência? Nem todos conseguem responder ao mal com o bem e muitos acabam por devolver aquilo que receberam. A escola torna-se para eles uma "válvula de escape", um local catártico de alívio da tensão e de expressão das frustrações. O professor é o "saco de pancadas" responsável por aguentar contra si toda a negatividade desta desforra contra a sociedade; deste acúmulo de atos e palavras voltados para aquilo que Freud chamou de "pulsão de morte"(2010).

Diante disso tudo, será que basta uma prova escrita para avaliar quem pode ser um bom professor ou não? Será possível avaliar o desempenho deste profissional sem uma análise séria e contínua de sua atuação em sala de aula e fora dela, agindo como eterno pesquisador e organizador corresponsável por um espaço escolar plural e democrático? O estabelecimento desta avaliação é aplicar aos profissionais da Educação o mesmo que se espera que eles apliquem aos alunos no modelo tradicional da "educação bancária"; é um mero instrumento repressor que visa dividir para dominar e que deseja mais disciplinar que trazer conhecimento. Conhecimento, aliás, que jamais poderá ser devidamente avaliado por qualquer instrumento classificatório massivo.

A própria LDB reconhece que um instrumento avaliativo deste caráter é falho e por isso estipula que o aspecto qualitativo deve sempre sobrepor-se ao quantitativo. É para que esta prática venha de fato a ocorrer que se realizam os conselhos de classe numa escola. Constituem eles uma ocasião propícia para que a lógica de enaltecimento irrestrito da avaliação seja rompida e se reafirme o valor intrínseco da relação professor-aluno. Algo que não pode ser quantificado e mensurado, mas que permite ao docente uma visão muito mais ampla e geral daquele educando que uma simples nota. Algo que rompe com a reificação que faz das pessoas meros números e devolve-lhes o caráter complexo de seres humanos, com todas suas potencialidades, males e contradições.

Aos docentes submetidos a tal avaliação credenciadora, no entanto, não será dado este direito a ser contemplado em sua condição humana. Terá ele o valor de um dado numérico; será assim classificado e hierarquizado, como um objeto qualquer. Fazendo isto com a classe docente, desumanizando-a ainda mais, espera-se desmantelar toda e qualquer sobrevivência da Pedagogia de Paulo Freire nas escolas brasileiras. Almeja-se, assim, acabar com qualquer chance que elas ainda tenham de formar mentes pensantes e fazer delas meras fábricas de consumidores dependentes e trabalhadores obedientes. Para o capitalismo, não interessa a reflexão, mas o capital. Como bem mostrou Marx (1999), o auge deste sistema está no ato de transformar tudo em mercadoria, o que produz a objetificação do ser humano e a humanização da mercadoria, 
de modo a parecer que é a mercadoria quem nos governa e não o oposto. Daí a quase onipresença, na atualidade, de um termo que denota este caráter reificador das relações de produção capitalistas: o "mercado". Faz-se tudo em nome do mercado; anseia-se por satisfazê-lo; há grande medo em desagradá-lo ou em não entender suas vontades. Como se o mercado tivesse vida; como se as mercadorias pensassem e falassem por conta própria. Enquanto isso, milhões de seres humanos são condenados à morte pela fome, pela sede, pelas más condições sanitárias ou pelas guerras que interessam apenas ao grande capital. A vida não tem valor; o dinheiro sim. Quando essa lógica invade e se apodera da escola, como esperar algo diferente da desumanização que trata as pessoas como coisas? É o que tem sido buscado pelas forças conservadoras que defendem os interesses da grande burguesia.

\section{Referências}

BOURDIEU, Pierre. A excelência e os valores do Sistema de Ensino Francês. In: BOURDIEU, Pierre. A economia das trocas simbólicas. Introdução, organização e seleção de Sergio Miceli. $6^{\mathrm{a}}$ edição; $2^{\mathrm{a}}$ reimpressão. Coleção estudos. São Paulo: Perspectiva, 2009, pp. 231-267.

BOURDIEU, P.; PASSERON, J-C. Les héritiers: les étudiants et la culture. Paris: Les Editions de Minuit, 1964.

BRASIL. Câmara dos Deputados. PL 1088/2007. Altera a Lei no 9.394, de 20 de dezembro de 1996, para instituir o exame nacional de certificação como pré-requisito para o exercício do magistério na educação básica e dá outras providências. Brasília, DF. Disponível em: $<$ http://www.camara.gov.br/proposicoesWeb/prop_mostrarintegra?codteor=460602\&filename $=$ PL+1088/2007>. Acesso em 26/09/2016.

BRASIL. Câmara dos Deputados. PL 6003/2013. Altera os arts. 9o, 35 e 36 da Lei no 9.394, de 20 de dezembro de 1996, de diretrizes e bases da educação nacional. Brasília, DF. Disponível em $:<$ http://www.camara.gov.br/sileg/integras/1200518.pdf > . Acesso em 25/09/2016.

BRASIL. Câmara dos Deputados. PL 6114/2009. Institui o Exame Nacional de Avaliação do Magistério da Educação Básica - Enameb. Brasília, DF. Disponível em: <http://www.camara.gov.br/proposicoesWeb/prop_mostrarintegra;jsessionid=645B4F0BFB51DDD889F7F7686889DA98. proposicoesWeb1? codteor $=6959618$ filename $=P L+6114 / 2009>$. Acesso em 26/09/2016.

BRASIL. LEI No 9.394, DE 20 DE DEZEMBRO DE 1996. Estabelece as diretrizes e bases da educação nacional. Disponível em: <http://www.planalto.gov.br/ccivil_03/leis/L9394.htm>. Acesso em 26/09/2016.

BRASIL. Senado Federal. PLS 193/2016. Inclui entre as diretrizes e bases da educação nacional, de que trata a Lei no 9.394, de 20 de dezembro de 1996, o "Programa Escola sem Partido". Brasília, DF. Disponível em : <http://legis.senado.leg.br/diarios/BuscaDiario?tipDiario=1\&da$\mathrm{tDiario}=04 / 05 / 20168$ paginaDireta=00179 $>$. Acesso em 25/09/2016.

EDUCAÇÃO E SOCIEDADE. Privatização e Militarização: Ameaças Renovadas à Gestão Democrática da Escola Pública. Editorial. EDUCAÇÃO E SOCIEDADE. vol.37, no.134, Campinas Jan./Mar. 2016. Disponível em: <http://www.scielo.br/scielo.php?script=sci_arttext\&pid=S0101-73302016000100001 >. Acesso em 08/07/2017.

FERNANDES, D. Pesquisa põe Brasil em topo de ranking de violência contra professores. BBC Brasil. Disponível em: <http://www.bbc.com/portuguese/noticias/2014/08/140822_salasocial_eleicoes_ocde_valorizacao_professores_brasil_daniela_rw>. Acesso em 08/07/2017.

FOUCAULT, M. Vigiar e punir. 1a edição. São Paulo: Vozes, 2015, 328 p. 
FREIRE, P. Pedagogia da autonomia: saberes necessários à prática educativa. Rio de Janeiro: Paz e Terra, 2011a.

FREIRE, P. Pedagogia da esperança: um reencontro com a pedagogia do oprimido. Rio de Janeiro: Paz e Terra, 2011b.

FREIRE, P. Pedagogia do oprimido. Rio de Janeiro: Paz e Terra, 2011c.

FREUD, S. "Além do princípio do prazer”. In: “O homem dos lobos” e outros textos (19171920). São Paulo: Companhia das Letras, 2010.

GARDNER, H. A nova ciência da mente: uma história da revolução cognitiva. São Paulo: EDUSP, 2003.

GENTILI, P. Neoliberalismo e educação: manual do usuário. In: SILVA, T. T. da \& GENTILI, P. (Orgs.). Escola S.A.: quem ganha e quem perde no mercado educacional do neoliberalismo. Brasília, DF: CNTE, 1996, p. 9-49. Também disponível em: http://static.recantodasletras.com. br/arquivos/4002523.pdf. Acesso em 08/07/2017.

GLOBO. Governo japonês pede cancelamento de cursos de Humanas em universidades. Globo. Rio de Janeiro, 16/09/2015. Disponível em : <http://oglobo.globo.com/sociedade/educacao/governo-japones-pede-cancelamento-de-cursos-de-humanas-em-universidades-17506865 > . Acesso em 25/09/2016.

LOPES, M. J. Prova de avaliação de professores é caso raro na Europa. Público. Lisboa, 18/12/2013. Disponível em: <https:/www.publico.pt/sociedade/noticia/prova-de-avaliacao-de -professores-e-caso-raro-na-europa-1616712 >. Acesso em 26/09/2016.

LOPES, M. J. e SANCHES, A. Quase $\mathbf{8 6 \%}$ dos candidatos a professores passam na prova de avaliação. Público. Lisboa, 04/08/2014. Disponível em: < https:/www.publico.pt/sociedade/noticia/quase-87-dos-candidatos-a-professores-passam-na-prova-de-avaliacao-1665395>. Acesso em 26/09/2016.

LOUZADA, V.; MARQUES, R. Políticas de Regulação para a Educação no Brasil: Interfaces entre Currículo, Avaliação e Formação Docente. In: e-Curriculum,v.13, n.04, p. 711 - 732 out./ dez.2015 < http://revistas.pucsp.br/index.php/curriculum/article/view/25244/18778 > Acesso em 13/04/2016.

MARX, K. A ideologia alemã. 1ª edição. São Paulo: Boitempo, 2007.

MARX, K. El Capital: Crítica de la Economía Política. Vol. I. Ciudad de México: Fondo de Cultura Económica, 1999, 851 p.

PAVLOV, I. P. Conditioned reflexes. Oxford: Oxford University Press, 1927, 430 p.

RUIVO, J. Avaliar professores é fácil? Público. Lisboa, 15/12/2015. Disponível em: <https://www.publico.pt/sociedade/noticia/avaliar-professores-e-facil-1717391>. Acesso em 26/09/2016.

SALDAÑA, P.; SANTOS, B. F.; TOLEDO; L. F. Escolas públicas e privadas da mesma 'classe social' têm médias iguais no Enem. Estado de São Paulo. São Paulo,23/12/2014. Disponível em: <http://educacao.estadao.com.br/noticias/geral,escolas-publicas-e-privadas-da-mesmaclasse-social-tem-medias-iguais-no-enem,1611102> Acesso em 09/11/2016.

SENRA, R. 'Professores reclamam mais do medo que do salário', diz psiquiatra. In: BBC Brasil. Disponível em: <http:/www.bbc.com/portuguese/noticias/2014/08/140818_salasocial_eleicoes_educacao_psiquiatra_rs $>$. Acesso em 06/07/2017.

SOUSA, S. M. Z. L.. Avaliação e Políticas Educacionais: Iniciativas em Curso no Brasil. In: Educação e Estado: as mudanças nos sistemas de ensino do Brasil e Paraná na década de 90 . HIDALGO, A. M. \& SILVA, I. L. F. Londrina: Ed. UEL, 2001.

UNESCO. Professores no Brasil: impasses e desafios. GATTI, B. A.; BARRETTO, E. S. S. (coord). Brasília, 2009. 
${ }^{1}$ LOPES, M. J. Prova de avaliação de professores é caso raro na Europa. Público. Lisboa, 18/12/2013. Disponível em: < https://www.publico.pt/sociedade/noticia/prova-de-avaliacao-de-professores-e-caso-raro-na-europa-1616712 >. Acesso em 26/09/2016.

${ }^{2}$ LOPES, M. J. e SANCHES, A. Quase $86 \%$ dos candidatos a professores passam na prova de avaliação. Público. Lisboa, 04/08/2014. Disponível em: < https://www.publico.pt/sociedade/noticia/quase-87-doscandidatos-a-professores-passam-na-prova-de-avaliacao-1665395 >. Acesso em 26/09/2016.

${ }^{3}$ GLOBO. Governo japonês pede cancelamento de cursos de Humanas em universidades. Globo. Rio de Janeiro, 16/09/2015. Disponível em : <http://oglobo.globo.com/sociedade/educacao/governo-japones-pede-cancelamento-de-cursos-de-humanas-em-universidades-17506865>. Acesso em 25/09/2016.

${ }^{4}$ SALDAÑA, P.; SANTOS, B. F.; TOLEDO; L. F. Escolas públicas e privadas da mesma 'classe social' têm médias iguais no Enem. Estado de São Paulo. São Paulo, 23/12/2014. Disponível em: <http://educacao. estadao.com.br/noticias/geral,escolas-publicas-e-privadas-da-mesma-classe-social-tem-medias-iguais-no -enem,1611102> Acesso em 09/11/2016.

${ }^{5}$ FERNANDES, D. Pesquisa põe Brasil em topo de ranking de violência contra professores. In: BBC Brasil. Disponível em: < http://www.bbc.com/portuguese/noticias/2014/08/140822_salasocial_eleicoes_ocde_valorizacao_professores_brasil_daniela_rw>.Acesso em 06/07/2017.

${ }^{6}$ SENRA, R. 'Professores reclamam mais do medo que do salário', diz psiquiatra. In: BBC Brasil. Disponível em: http://www.bbc.com/portuguese/noticias/2014/08/140818_salasocial_eleicoes_educacao_psiquiatra_rs. Acesso em 06/07/2017.

* Doutor em Literatura de Língua Portuguesa no Centro de Literarura Portuguesa da Faculdade de Letras da Universidade de Coimbra, Coimbra, Portugal.

\section{Correspondência}

Rodrigo do Prado Bittencourt - Instituto Moduo Educar, Instituto Moduo Educar. Rua Prudente de Moraes, 743. Centro. CEP: 13201004. Jundiaí, São Paulo, Brasil.

E-mail: rodrigopbittencourt@gmail.com

Recebido em 09 de novembro de 2016

Aprovado em 20 de dezembro de 2017 